\title{
Effects of black soy peptide supplementation on blood pressure and oxidative stress: a randomized controlled trial
}

\begin{abstract}
Jung Hyun Kwak ${ }^{1}$, Minjoo Kim ${ }^{2,3}$, Eunhee Lee ${ }^{2}$, Sang-Hyun Lee ${ }^{4}$, Chang-Won $\mathrm{Ahn}^{5}$ and Jong Ho Lee
Black soy peptides have been shown to possess properties that may decrease blood pressure (BP). To examine the effects of black soy peptide supplementation on BP and oxidative stress in subjects with prehypertension or stage I hypertension, 100 participants with an initial untreated systolic blood pressure (SBP) of $130-159 \mathrm{~mm} \mathrm{Hg}$, diastolic blood pressure (DBP) of $80-99 \mathrm{~mm} \mathrm{Hg}$ or both were enrolled. Participants were randomly assigned to either a group ingesting supplement containing $4.5 \mathrm{~g}$ black soy peptides daily or a placebo group for 8 weeks. SBP and DBP decreased after 8-week black soy peptide supplementation versus controls $(P<0.001)$. At 8 weeks, SBP decrease was significantly greater for the black soy peptide group $(-9.69 \pm 12.37 \mathrm{~mm} \mathrm{Hg})$ than for the control group $(-2.91 \pm 13.29 \mathrm{~mm} \mathrm{Hg})$ after adjusting for the baseline levels $(P=0.015)$. Plasma malondialdehyde (MDA) and urinary 8-epi-prostaglandin $F_{2 \alpha}$ decreased $(P=0.004$ and $P=0.046$, respectively) and plasma superoxide dismutase (SOD) activity increased $(P<0.001)$ following 8 weeks of black soy peptide supplementation versus baselines. The MDA decreases $(P=0.022)$ and SOD activity and nitric oxide (NO) increases $(P=0.022$ and $\boldsymbol{P}<0.001$, respectively) were greater for the black soy peptide group than for the control group. Changes in SBP negatively correlated with changes in NO $(r=-0.343, P=0.001)$. Changes in angiotensin-converting enzyme activity negatively correlated with NO decreases $(r=-0.490, P<0.001)$ and SOD activity increases $(r=-0.338, P=0.001)$. Black soy peptide dietary supplementation significantly reduces SBP and oxidative stress in patients with prehypertension and stage I hypertension.
\end{abstract}

Hypertension Research (2013) 36, 1060-1066; doi:10.1038/hr.2013.79; published online 8 August 2013

Keywords: black soy peptide; blood pressure; oxidative stress

\section{INTRODUCTION}

Black soy peptides possess properties that may be advantageous to treat metabolic syndrome. These effects include lowering blood pressure $(\mathrm{BP})^{1}$ as well as reducing blood glucose $e^{2}$ and insulin resistance. ${ }^{3}$ Beneficial effects of black soy peptides are also suggested in obesity. ${ }^{4,5}$ As metabolic syndrome is a significant public health problem worldwide, ${ }^{6}$ biologically active peptides, including black soy peptide, may be of vital interest in maintaining a healthy population.

Elevated BP is a major independent risk factor for cardiovascular disease. ${ }^{7}$ Angiotensin-converting enzyme (ACE) catalyzes the conversion of inactive angiotensin I to bioactive angiotensin II in the circulatory system and in tissues and can lead to both elevated BP and to tissue damage by increased oxidative stress. ${ }^{8}$ Anti-ACE inhibitory drugs are clinical mainstays and are widely used for hypertension therapy. ${ }^{9}$ However, because synthetic ACE inhibitors have side effects that include cough, loss of taste sensation and renal impairment, natural ACE inhibitors without these side effects are desirable. Soybean peptide fractions isolated from the Korean fermented soybean paste exert ACE-inhibitory activity in vitro. ${ }^{10}$ Additionally, Shin et al. ${ }^{1}$ purified and identified an ACE-inhibitory peptide, His-His-Leu, from fermented soybean paste. This peptide is also found in black soy peptides. Moreover, the synthetic tripeptide His-His-Leu resulted in a significant decrease of aortic ACE activity and lowered systolic blood pressure (SBP) in spontaneously hypertensive rats. However, until now, most of the physiological effects of black soy peptides have been explored in vitro or in animal models. Human clinical studies are limited or nonexistent.

We hypothesized that black soy peptide supplementation would reduce BP and oxidative stress in persons with prehypertension or stage I hypertension. We designed a randomized, double-blind, placebo-controlled study to assess $\mathrm{BP}$, oxidative stress and $\mathrm{ACE}$ and

${ }^{1}$ Yonsei University Research Institute of Science for Aging, Yonsei University, Seoul, Korea; ${ }^{2}$ National Leading Research Laboratory of Clinical Nutrigenetics/Nutrigenomics, Department of Food and Nutrition, College of Human Ecology, Yonsei University, Seoul, Korea; ${ }^{3}$ Department of Food and Nutrition, Brain Korea 21 Project, College of Human Ecology, Yonsei University, Seoul, Korea; ${ }^{4}$ Department of Family Practice, National Health Insurance Corporation, Ilsan Hospital, Goyang-si, Korea and ${ }^{5}$ Research and Development Center, Nong Shim Co., Ltd., Dongjak-Gu, Seoul, Korea

Correspondence: Dr JH Lee, National Leading Research Laboratory of Clinical Nutrigenetics/Nutrigenomics, Department of Food and Nutrition, College of Human Ecology, Yonsei University, 134 Shinchon-Dong, Seodaemun-Gu, Seoul 120-749, Korea.

E-mail: jhleeb@yonsei.ac.kr

Received 14 January 2013; revised 15 April 2013; accepted 9 May 2013; published online 8 August 2013 
nitric oxide (NO) activities following an 8-week treatment with black soy peptide supplementation.

\section{METHODS}

\section{Participants and study design}

We recruited study participants from the outpatient clinics at Ilsan hospital (Ilsan, Korea) and through advertisements in local newspapers. Trial participants included men and women aged 30-65 years who had an average SBP between 130 and $159 \mathrm{~mm} \mathrm{Hg}$, average diastolic blood pressure (DBP) between 80 and $99 \mathrm{~mm} \mathrm{Hg}$ or both, based on an average of six measurements during two screening visits. Exclusion criteria included previous diagnosed clinical hypertension, self-reported use of antihypertensive medication, abnormal liver or renal function, history of cardiovascular disease, kidney disease, cancer, thyroid or pituitary disease or any other serious life-threatening illness that required regular medical treatment. We also excluded women who were pregnant, breast feeding or intending to become pregnant during the time of study.

One hundred subjects with prehypertension and newly diagnosed (by us) stage I hypertension were initially enrolled in this study. Of these, 91 participants met all eligibility criteria and were randomly assigned to the treatment groups. Written informed consent was obtained from all the subjects, and the protocol was approved by the Ethics Committee of Yonsei University and the Institutional Review Board of the National Health Insurance Corporation, Ilsan Hospital, Ilsan, Korea. All clinical studies were carried out in accordance with the guidelines of the Declaration of Helsinki.

\section{Intervention}

One hundred subjects were initially assigned into two groups: the test group $(n=50)$ and the control group $(n=50)$, using computer-generated randomization. Of these 100 participants, 9 dropped out because of poor protocol compliance (control, $n=2$; test, $n=2$ ) or for personal reasons (control, $n=2$; test, $n=3$ ). Participants were supplied with 84 pouches of placebo (casein) or black soy peptide ( 3 pouches day ${ }^{-1}$ ) at 0 -week and 4 -week visits. Test group subjects $(n=45)$ received pouches containing black soy peptides $\left(4.5 \mathrm{~g} \mathrm{day}^{-1}\right.$ total soy peptides for 8 weeks). The control group $(n=46)$ received pouches containing casein that had a similar appearance to that of the black soy peptide tablet. Kwak et al. ${ }^{11}$ conducted a pilot study in 32 subjects with fasting glucose $\geqslant 90 \mathrm{mg} \mathrm{dl}^{-1} \mathrm{dl}$; black soy peptide ( $1.5 \mathrm{~g}, 3.0 \mathrm{~g}$ or $4.5 \mathrm{~g}$, dose-dependently) and placebo was randomly provided to study participants. From this study, high dose of the black soy peptide group $\left(4.5 \mathrm{~g} \mathrm{day}^{-1}\right)$ showed a greater tendency of reduction in body weight $(1.1 \pm 0.92 \mathrm{~kg})$ than the other groups (data unpublished). Based on this data, we confirmed that a black soy peptide supplement may help to control body weight and body fat mass in overweight and obese subjects associated with plasma leptin levels. Also, tendentious decrease was shown in DBP after 12-week intervention (before: $86.4 \pm 2.19$, after: $84.5 \pm 2.23$ ). Therefore, we chose the dose of black soy peptide $4.5 \mathrm{~g} \mathrm{day}^{-1}$ in this study. Both the black soy peptide supplement and placebo were provided by Nong Shim (Dongjak-Gu, Seoul, Korea). The black soy peptide is composed of low molecular weight amino acid $(10000 \mathrm{kDa})$, and the major amino acids were arginine and leucine (see Supplementary Information). In a previous study, a randomized, controlled trial in Korean adults showed a statistically significant reduction in BP related to nattokinase supplementation during the 8 -week intervention. ${ }^{12}$ Therefore, on the basis of this result, we chose the 8-week intervention of black soy peptide supplementation in this study.

During the intervention, we instructed study participants to continue their current food-intake patterns and lifestyles so that total energy intake and energy expenditure would be constant during the course of trial. Participants brought back unconsumed pouches at their 4- and 8-week follow-up visits. The dietitian counted the number of returned pouches, and we used this to assess the participants' adherence to their assigned intervention.

\section{Assessment of food intake and physical activity}

Usual food intake was assessed by a 24 -h recall method, which uses a semiquantitative food frequency questionnaire. ${ }^{13}$ All subjects got written and oral instructions by a dietitian on how to complete 3 -days week ${ }^{-1}$ ( 2 weekdays and 1 weekend day) dietary records. On the sheet, subjects wrote the kinds and amounts of food they consumed. Participants were interviewed to confirm whether they were following the program well and were assessed for weight changes. Dietary energy values and nutrient content from complete 3-day dietary records were calculated using the Computer-Aided Nutritional Analysis Program (CAN-pro 2.0, Korean Nutrition Society, Seoul, Korea).

Total energy expenditure $\left(\mathrm{kcalday}^{-1}\right)$ was calculated from the basal metabolic rate, 24-h physical activity ${ }^{14}$ and the food-specific dynamic action. Basal metabolic rate for each subject was calculated with the Harris-Benedict equation. ${ }^{15}$

\section{Anthropometric parameters, BP and blood collection}

Body weight and height were measured in the morning in unclothed subjects without shoes to calculate body mass index (body mass index; $\mathrm{kg} \mathrm{m}^{-2}$ ). BP was measured with a Random-zero Sphygmomanometer (Hico Medical Co., Ltd., Chiba, Japan). BP readings were measured in both the arms and recorded from the arm indicating the higher $\mathrm{BP}$, using appropriately sized cuffs, after the participant had sat quietly for $5 \mathrm{~min}$. We obtained three BP measurements at each visit and differences among the three SBP readings were always $<5 \mathrm{~mm}$ Hg. BP was measured again at the 4- and 8-week follow-up visits. Participants were instructed not to smoke or drink alcohol for at least $30 \mathrm{~min}$ before BP measuring. Patients were also instructed to undergo 12-h fast period before the initial blood draw and before follow-up visits. Venous blood specimens were collected in EDTA-treated and plain tubes, then centrifuged to produce plasma or serum that was stored at $-70{ }^{\circ} \mathrm{C}$ until analysis.

\section{Serum lipid profile, fasting glucose, insulin concentration and} homeostasis model assessment-insulin resistance (HOMA-IR) Fasting serum total-cholesterol and triglyceride concentrations were measured using commercially available kits on an ADVIA 2400 Clinical Chemistry System (Siemens, Tarrytown, NY, USA). After precipitation of ApoB-containing lipoproteins with dextran sulfate-magnesium, high-density lipoprotein (HDL)cholesterol was measured in the supernatant by an enzymatic method. Low-density lipoprotein (LDL)-cholesterol was indirectly estimated in participants with serum triglyceride concentration $<400 \mathrm{mgdl}^{-1}$ using the Friedewald formula: LDL-cholesterol $=$ total-cholesterol $-($ HDL-cholesterol + (triglycerides/5)). Fasting glucose levels were measured using a hexokinase method with an ADVIA 2400 Clinical Chemistry System (Siemens). Insulin levels were measured by radioimmunoassay using a commercial kit (Immuno Nucleo Corporation, Stillwater, MN, USA). Insulin resistance was calculated from the HOMA using the following equation: HOMA-IR = (fasting insulin $\left(\mu \mathrm{IU} \mathrm{ml} l^{-1}\right) \times$ fasting glucose $\left.\left(\mathrm{mmoll}^{-1}\right)\right) / 22.5$.

Urinary 8-epi-prostaglandin $\mathrm{F}_{2 \alpha}(8$-epi-PGF $2 \alpha)$, serum highsensitivity C-reactive protein and plasma malondialdehyde (MDA) measurements

Urinary 8-epi-PGF $2 \alpha$ was measured using an enzyme immunoassay (BIOXYTECH urinary 8-epi-PGF ${ }_{2 \alpha}$ TM Assay Kit, OXIS International, Portland, OR, USA). Urinary creatinine levels were determined using the alkaline picrate (Jaffe) reaction. Serum high-sensitivity C-reactive protein concentrations were measured using an ADVIA 2400 (Siemens) with a commercially available, high-sensitivity CRP-Latex(II) X2 kit (Siemens). Plasma MDA was measured using thiobarbituric acid-reactive substances (TBARS Assay Kit; Zepto-Metrix, Buffalo, NY, USA).

\section{Renin, ACE, plasma superoxide dismutase (SOD) activity and NO} measurement

Plasma renin activity was measured using the GAMMA-10 competitive binding radioimmunoassay kit (Shinjin Medics Inc., Koyang, Korea). After a reaction with plasma renin enzyme activity and renin substrate, the amount of angiotensin I activity was measured. ACE was measured using an enzymatic assay on an ADVIA 2400 Clinical Chemistry System (Siemens). Plasma SOD activity was measured based on the generation of superoxide radicals produced by xanthine oxidase and hypoxanthine using a kit (Cayman Chemical, Ann Arbor, MI, USA). Absorbance was read at $450 \mathrm{~nm}$ with a Wallac Victor ${ }^{2}$ multilabel plate reader (Perkin Elmer Life Sciences, Turka, Finland). 
Serum total NO was determined based on the enzymatic conversion of nitrate to nitrite by nitrate reductase, as analyzed using the Total NO/Nitrite/Nitrate Parameter Assay kit (R\&D Systems, Minneapolis, MN, USA). The resultant color reaction was read using a VERSAmax microplate reader (Molecular Devices, Sunnyvale, CA, USA) at $540 \mathrm{~nm}$.

\section{Data analyses}

Statistical analyses were performed using the SPSS version 12.0 for Windows (SPSS, Chicago, IL, USA). Skewed variables were logarithmically transformed

\section{Table 1 Baseline clinical characteristics and nutrient intake}

\begin{tabular}{lccc}
\hline & \multicolumn{3}{c}{ Black soy peptide } \\
& Control $(\mathrm{n}=46)$ & $(\mathrm{n}=45)$ & P-values \\
\hline Age (years) & $44.8 \pm 12.03$ & $46.8 \pm 11.83$ & 0.427 \\
Male (\%) & 49.1 & 50.9 & 0.725 \\
Weight (kg) & $71.8 \pm 16.8$ & $72.0 \pm 16.9$ & 0.197 \\
BMI (kg m ${ }^{-2}$ ) & $25.4 \pm 3.90$ & $24.5 \pm 2.85$ & 0.193 \\
Current cigarette smoker (\%) & 57.9 & 42.1 & 0.472 \\
Current alcohol drinker (\%) & 53.6 & 46.4 & 0.299 \\
Total-cholesterol (mmol I-1) & $5.24 \pm 0.98$ & $5.07 \pm 0.98$ & 0.402 \\
LDL-cholesterol (mmol I $\left.^{-1}\right)^{\mathrm{a}}$ & $3.08 \pm 0.86$ & $2.97 \pm 0.91$ & 0.536 \\
HDL-cholesterol (mmol I-1) & $1.41 \pm 0.33$ & $1.32 \pm 0.27$ & 0.185 \\
Triglyceride (mmol I-1) & $1.49 \pm 0.84$ & $1.55 \pm 0.92$ & 0.841 \\
hs-CRP (mg I-1) & $1.36 \pm 1.53$ & $1.16 \pm 1.26$ & 0.440 \\
& & & \\
Estimates of daily nutrient intakes & & & \\
$\quad$ Total calorie intake (kcal) & $2300.3 \pm 276.57$ & $2296.1 \pm 245.27$ & 0.940 \\
Carbohydrate (\% of energy) & $61.9 \pm 1.04$ & $61.8 \pm 1.08$ & 0.567 \\
Protein (\% of energy) & $16.5 \pm 0.71$ & $16.4 \pm 0.59$ & 0.955 \\
Fat (\% of energy) & $22.2 \pm 0.75$ & $22.1 \pm 0.85$ & 0.349 \\
Sodium (mg) & $6919.0 \pm 1779.9$ & $6656.0 \pm 1442.9$ & 0.441 \\
Total energy expenditure (kcal) & $2324.9 \pm 385.33$ & $2271.2 \pm 299.62$ & 0.459
\end{tabular}

Abbreviations: BMI, body mass index; hs-CRP, high-sensitivity C-reactive protein; HDL, highdensity lipoprotein; LDL, low-density lipoprotein.

${ }^{a}$ Means \pm s.d. tested by logarithmic transformation; $P$-values derived from independent $t$-test. for statistical analyses. Frequency was tested with the chi-squared test. Independent $t$-tests were used to compare the effects between the black soy peptide and control group. Paired $t$-tests were used to test between baseline and follow-up values. General linear model analyses were also performed, with adjustments for the baseline values. Pearson's and partial correlation coefficients were determined to examine the relationships between variables. For descriptive purposes, mean values are presented using untransformed values. Results are expressed as the mean \pm s.d. A two-tailed $P$-value $<0.05$ was considered statistically significant.

\section{RESULTS}

Baseline clinical characteristics and nutrient intake

Table 1 shows the baseline clinical characteristics and nutrient intake of the study subjects. There were no significant differences between the two groups. Black soy peptide supplementation had no significant effect on weight, body mass index, fasting glucose levels, lipid profiles, high-sensitivity C-reactive protein levels, estimates of daily nutrient intake and total energy expenditure. Also, after the 12-week intervention, the test and placebo group did not show any significant changes in these variables. Additionally, black soy peptide supplementation did not affect any of the safety parameters in subjects, including liver and kidney function tests and complete blood counts (data not shown).

\section{Change in BP after black soy peptide supplementation}

Figure 1 shows the changes in SBP, DBP and pulse pressure from baseline to the 4- and 8-week follow-up visits according to the intervention assignment. Both SBP and DBP decreased after 8-week black soy peptide supplementation versus baseline ( $P>0.001$ in both the cases). After 4 weeks, the mean SBP change was $-6.69 \pm 13.13 \mathrm{~mm} \mathrm{Hg}$ in the black soy peptide group and $-4.04 \pm 14.34 \mathrm{~mm} \mathrm{Hg}$ in the control group. At the 8 -week visit, the SBP decrease was significantly greater in the black soy peptide group $(-9.69 \pm 12.37 \mathrm{~mm} \mathrm{Hg})$ than in the control group $(-2.91 \pm 13.29 \mathrm{~mm} \mathrm{Hg})$, both before $(P=0.014)$ and after $(P=0.015)$ adjusting for the baseline levels.

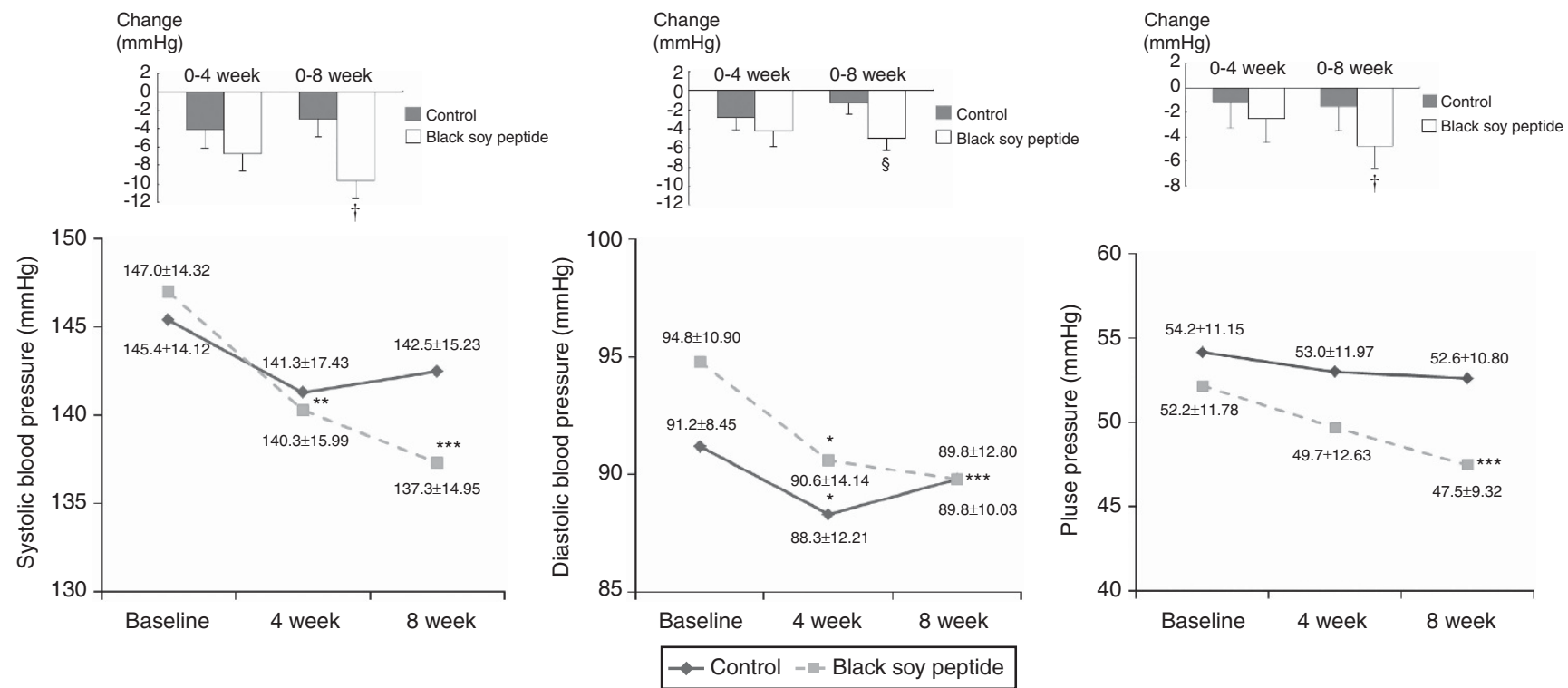

Figure 1 The effect of black soy peptide supplementation on systolic blood pressure, diastolic blood pressure and pulse pressure. Data are presented as means \pm s.d. ${ }^{*} P<0.05,{ }^{*} P<0.01$ and ${ }^{* * *} P<0.001$ compared with baseline within the group. ${ }^{\dagger} P<0.05$ and ${ }^{\S} P<0.10$ compared with the changed value of the control group after adjusting for the baseline value. Each comparison was evaluated by $t$-test. $P$-values are for comparing differences among the change values; $P$-values $<0.05$ were considered statistically significant differences. Changes are absolute differences. 
Average DBP was reduced by $4.20 \pm 11.48 \mathrm{~mm} \mathrm{Hg}$ in the black soy peptide group and $2.87 \pm 8.62 \mathrm{~mm} \mathrm{Hg}$ in the control group at the 4 -week follow-up visit. At the 8-week visit, the DBP decrease was significantly greater for the black soy peptide group $(-4.98 \pm$ $8.60 \mathrm{~mm} \mathrm{Hg})$ than for the control group $(-1.37 \pm 7.81 \mathrm{~mm} \mathrm{Hg}$; $P=0.039)$, but this difference disappeared after adjusting for the baseline levels $(P=0.084)$. In addition, pulse pressure decreased after the 8 -week black soy peptide supplementation versus baseline $(P=0.007)$. At the 8 -week visit, the pulse pressure decrease was significantly greater in the black soy peptide group $(-4.71 \pm$ $11.19 \mathrm{~mm} \mathrm{Hg})$ than in the control group $(-1.54 \pm 11.17 \mathrm{~mm} \mathrm{Hg})$ after $(P=0.024)$ adjusting for the baseline levels.

\section{Renin levels, ACE activity and homeostasis model} assessment-insulin resistance index

No significant differences were found in the initial renin levels and ACE activities between the two groups (Table 2, Figure 2). The decreased ACE activity (from baseline) in the black soy peptide group $\left(-3.77 \pm 15.56 \mathrm{Ul}^{-1}\right)$ tended to be greater than in the control group $\left(2.27 \pm 14.12 \mathrm{Ul}^{-1} ; P=0.061\right)$, but this tendency disappeared after adjusting for the baseline levels (Figure 2).

No significant differences were found in the initial levels of serum insulin, fasting glucose and HOMA-IR indices between the two groups (Table 2). The mean serum insulin level $(P=0.029)$ and HOMA-IR index $(P=0.030)$ in the black soy peptide group were significantly lower than those in the control group, after adjusting for the baseline levels.

\section{NO and oxidative stress markers}

The decrease in NO concentration in the black soy peptide group $\left(2.36 \pm 4.69 \mu \mathrm{moll}^{-1}\right)$ was significantly different from that in the control group $\left(-1.26 \pm 3.80 \mu \mathrm{moll}^{-1}\right)$ before $(P<0.001)$ and after $(P<0.001)$ adjusting for the baseline levels (Figure 2$)$. Serum total NO concentrations after 8 weeks were significantly higher in subjects supplemented with $4.5 \mathrm{~g}$ black soy peptide day ${ }^{-1}$ compared with that in the control group $(P=0.046)$. Both plasma MDA levels $(P=0.004$; Table 2) and urinary 8-epi-PGF ${ }_{2 \alpha}$ concentrations (1979.3 \pm 1024.4 versus $1843.9 \pm 1049.1 \mathrm{pg}$ per $\mathrm{mg}$ creatinine; $P=0.046$; Figure 2 ) were significantly decreased following 8 weeks of black soy peptide supplementation compared with the baseline. The decrease in plasma MDA concentration was significantly greater for the black soy peptide group than for the control group before $(P=0.007)$ and after $(P=0.022)$ adjusting for the baseline values. The change in urinary 8 -epi-PGF $2 \alpha$ concentration in the black soy peptide group tended to be different from that in the control group $(P=0.095)$ after adjusting for the baseline levels, although this did not achieve statistical significance. Urinary 8 -epi-PGF $2 \alpha$ concentration after 8 weeks were lower in subjects supplemented with black soy peptides compared with the control group $(P=0.044)$. Plasma SOD activity was significantly increased following 8 weeks of black soy peptide supplementation versus baseline $(P<0.001)$. The increased plasma SOD activity was significantly greater in the black soy peptide group than in the control group before $(P=0.020)$ and after $(P=0.022)$ adjusting for the baseline values (Table 2).

Relationship between changes in $\mathrm{BP}, \mathrm{ACE}$, total NO and oxidative stress markers

In all the subjects, SBP changes negatively correlated with serum total NO changes $(r=-0.343, P=0.001)$. Changes in ACE activity also negatively correlated with NO levels $(r=-0.490, P<0.001)$ and plasma SOD activity $(r=-0.338, P=0.001)$ but tended to positively
Table 2 Effects of 8-week black soy peptide supplementation on renin, oxidative stress markers and homeostasis model assessmentinsulin resistance (HOMA-IR) index

\begin{tabular}{|c|c|c|c|c|c|c|}
\hline & $\begin{array}{l}\text { Control } \\
(n=46)\end{array}$ & P-value & $\begin{array}{c}\text { Black soy } \\
\text { peptide } \\
(\mathrm{n}=45)\end{array}$ & P-value & P-value ${ }^{b}$ & P-value \\
\hline \multicolumn{7}{|c|}{$\operatorname{Renin}\left(n g m l^{-1} h^{-1}\right)$} \\
\hline Baseline $^{d}$ & $1.71 \pm 1.69$ & 0.662 & $1.64 \pm 1.46$ & 0.210 & 0.550 & \\
\hline Follow-up ${ }^{d}$ & $2.33 \pm 2.64$ & & $2.10 \pm 2.05$ & & 0.956 & \\
\hline Change & $0.62 \pm 2.66$ & & $0.46 \pm 2.22$ & & 0.753 & 0.657 \\
\hline \multicolumn{7}{|c|}{ Glucose $\left(\mathrm{mmol}^{-1}\right)$} \\
\hline Baseline $^{d}$ & $4.99 \pm 0.57$ & 0.258 & $5.06 \pm 0.65$ & 0.359 & 0.584 & \\
\hline Follow-up ${ }^{d}$ & $5.09 \pm 0.60$ & & $5.12 \pm 0.64$ & & 0.808 & \\
\hline Change & $0.10 \pm 0.56$ & & $0.06 \pm 0.07$ & & 0.305 & 0.875 \\
\hline \multicolumn{7}{|c|}{ Insulin $\left(\mathrm{pmol} \mathrm{I}^{-1}\right)$} \\
\hline Baseline $^{d}$ & $56.7 \pm 25.4$ & 0.105 & $57.7 \pm 31.7$ & 0.366 & 0.984 & \\
\hline Follow-up ${ }^{d}$ & $61.6 \pm 32.6$ & & $52.1 \pm 16.0$ & & 0.118 & \\
\hline Change & $4.98 \pm 25.1$ & & $-5.68 \pm 26.3$ & & 0.052 & 0.029 \\
\hline \multicolumn{7}{|l|}{ HOMA-IR } \\
\hline Baseline $^{d}$ & $1.84 \pm 0.90$ & 0.073 & $1.88 \pm 1.07$ & 0.512 & 0.911 & \\
\hline Follow-up ${ }^{d}$ & $2.02 \pm 1.04$ & & $1.71 \pm 0.58$ & & 0.167 & \\
\hline Change & $0.18 \pm 0.78$ & & $-0.17 \pm 0.89$ & & 0.049 & 0.030 \\
\hline \multicolumn{7}{|c|}{$M D A\left(n m o l m l^{-1}\right)$} \\
\hline Baseline $^{d}$ & $6.83 \pm 2.23$ & 0.897 & $7.30 \pm 1.77$ & 0.004 & 0.151 & \\
\hline Follow-upd & $6.80 \pm 1.85$ & & $6.42 \pm 1.28$ & & 0.374 & \\
\hline Change & $-0.04 \pm 1.62$ & & $-0.87 \pm 1.22$ & & 0.007 & 0.022 \\
\hline \multicolumn{7}{|c|}{ SOD activity (units $m l^{-1}$ ) } \\
\hline Baseline $^{d}$ & $14.6 \pm 4.27$ & 0.252 & $14.2 \pm 3.04$ & $<0.001$ & 0.792 & \\
\hline Follow-up ${ }^{d}$ & $14.8 \pm 4.31$ & & $16.0 \pm 4.54$ & & 0.217 & \\
\hline Change & $0.17 \pm 2.68$ & & $1.77 \pm 3.71$ & & 0.020 & 0.022 \\
\hline
\end{tabular}

Abbreviations: MDA, malondialdehyde; SOD, superoxide dismutase.

Means \pm s.d.

${ }^{a} P$-values derived from paired $t$-test.

b $P$-values derived from independent $t$-test.

${ }^{C} P$-values derived from independent $t$-test after adjusting for the baseline values.

${ }^{\mathrm{d}}$ Tested by logarithmic transformation.

correlate with plasma MDA levels $(r=0.202, P=0.061)$. Additionally, serum total NO changes correlated positively with plasma SOD activity $(r=0.414, P<0.001)$ and negatively with plasma MDA concentration $(r=-0.251, P=0.016)$ (Figure 3).

\section{DISCUSSION}

This randomized, double-blind, placebo-controlled study showed that black soy peptide dietary supplementation reduces SBP in individuals with prehypertension or stage I hypertension. This finding may have important clinical implications, because it is estimated that a $2 \mathrm{~mm} \mathrm{Hg} \mathrm{SBP} \mathrm{reduction} \mathrm{will} \mathrm{result} \mathrm{in} \mathrm{a} 6 \%$ reduction in fatal stroke and a $4 \%$ reduction in fatal coronary heart disease in the general population. ${ }^{16}$ Additionally, black soy peptide supplementation showed improved oxidative stress status, including a reduction in plasma MDA and urinary 8 -epi-PGF $2 \alpha$ and an increase in plasma SOD activity. Furthermore, SBP changes negatively correlated with changes in serum total NO concentrations. Increased serum NO negatively correlated with serum ACE activity and plasma MDA levels and was positively associated with increased SOD activity. This result suggests that the BP-lowering effects of black soy peptides may relate to improved oxidative stress status, enhanced NO production and decreased ACE activity. 

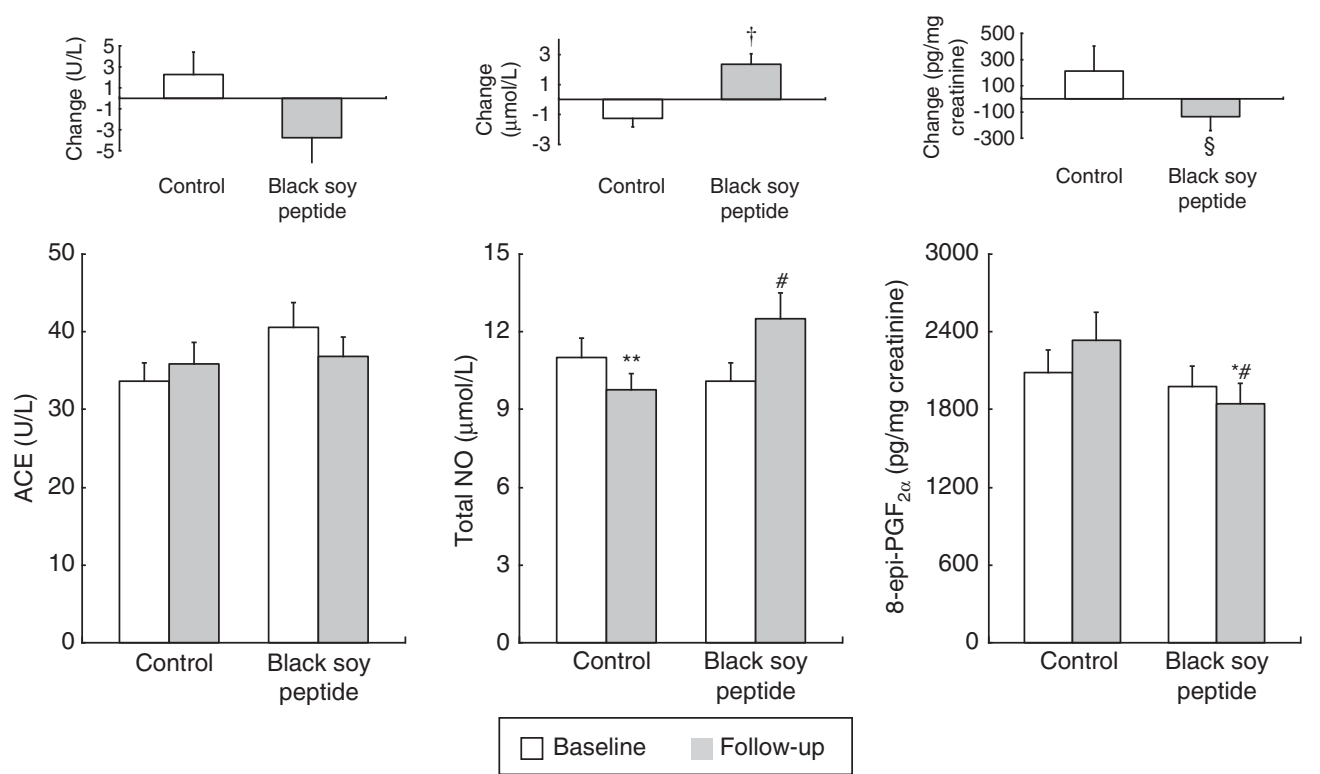

Figure 2 Effects of 8-week black soy peptide supplementation on angiotensin-converting enzyme (ACE) activity, serum total nitric oxide (NO) and urinary 8-epi-prostaglandin $F_{2 \alpha}$ (8-epi- $P_{G F} F_{2 \alpha}$ ). Data are presented as means \pm s.d. ${ }^{*} P<0.05$ and ${ }^{*} P<0.01$ compared with baseline within the group. ${ }^{\#} P<0.05$ compared with the control group. ${ }^{\dagger} P<0.05$ and ${ }^{\$} P<0.10$ compared with the changed value of the control group after adjusting for the baseline value. Each comparison was evaluated by $t$-test. $P$-values are for comparing differences among the change values; $P$-values $<0.05$ were considered statistically significant differences. Changes are absolute differences.
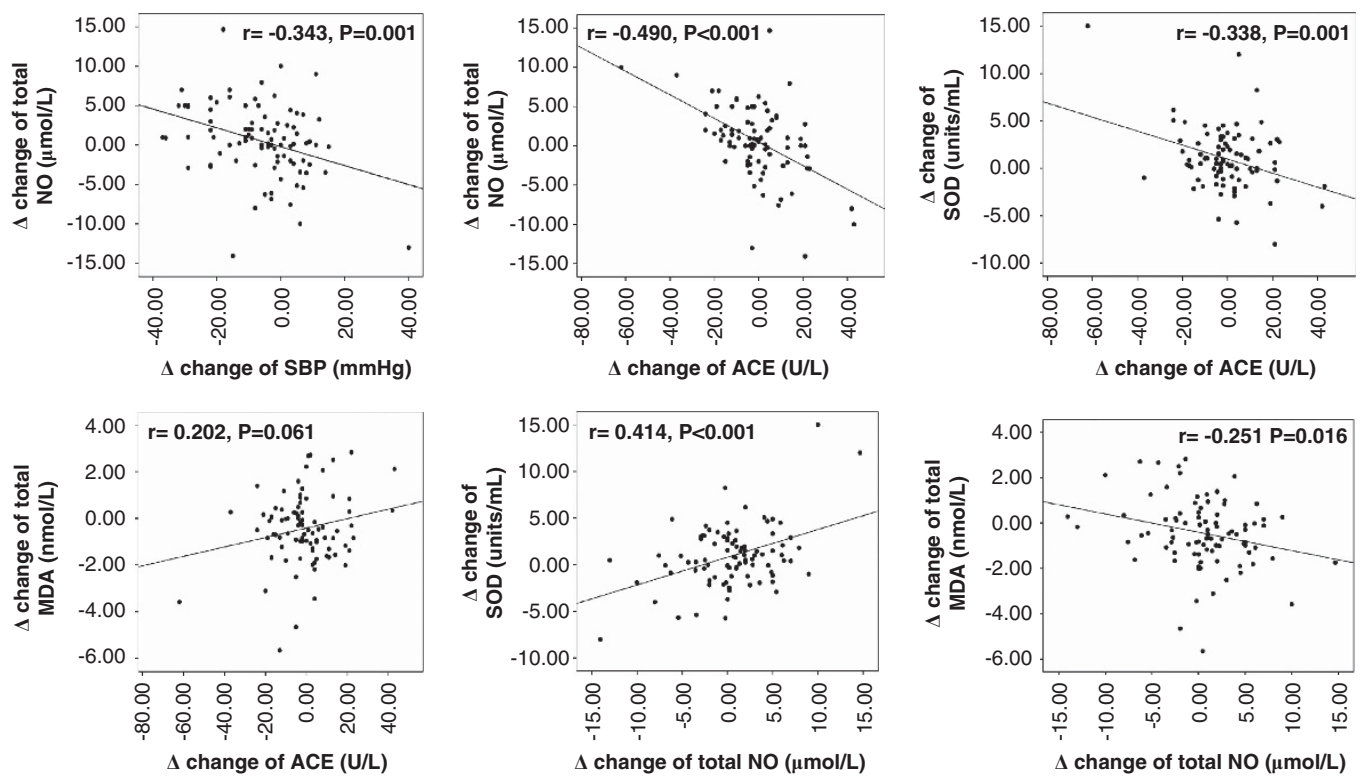

Figure 3 Relationships between change in systolic blood pressure (SBP), angiotensin-converting enzyme (ACE) activity, serum total nitric oxide (NO) and oxidative stress markers. $r$ : Pearson's correlation coefficient.

Although the effect of soy protein on BP in prehypertensive or hypertensive individuals has been reported, ${ }^{17}$ the effect of soy peptides has rarely been studied in hypertensive subjects. It has been suggested that soy protein hydrolysate lowers BP on account of the physiologically functional peptides it contains. ${ }^{18}$ The potency of an ACE inhibitor is usually expressed as an $\mathrm{IC}_{50}$ value, which is the inhibitor concentration leading to 50\% inhibition of ACE activity. Shin et al. ${ }^{1}$ demonstrated that the ACE-inhibitory peptide His-HisLeu, derived from the Korean fermented soybean paste, had an $\mathrm{IC}_{50}$ value of $2.2 \mu \mathrm{g} \mathrm{ml}^{-1}$ and exerted antihypertensive activity in vivo. Similarly, black soy peptides, which are used in the present study, contain this ACE-inhibitory peptide His-His-Leu. However, black soy peptide supplementation, which is differ from previous study, caused a $9.3 \%$ BP reduction but no significant ACE activity reduction was observed in present study. This suggests that black soy peptides may influence BP by mechanisms other than ACE inhibition. In fact, several antihypertensive agents have been suggested to lower BP through mechanisms that go beyond their primary actions as ACE inhibitors. ${ }^{19}$

Black soy peptides contain higher levels of arginine $(9.63 \%),{ }^{5}$ the metabolic precursor of the potent vasodilator NO, compared with the control casein protein $\left(3.51 \%\right.$ arginine residues). ${ }^{20}$ Intravenous 
arginine injection in humans substantially decreases BP and total peripheral resistance. ${ }^{21}$ Arginine supplementation in the diet has an antihypertensive effect in the animal hypertension model. ${ }^{22}$ In our study, there was a significant difference between the black soy peptide and control groups in changing NO levels. In turn, NO levels were negatively correlated with SBP and ACE activity. These findings suggest that the higher arginine content of soy-based products may partly account for the enhanced BP reduction versus the lower arginine content casein control. In addition to being a substrate for NO formation, arginine could modulate the renin-angiotensin system by inhibiting ACE activity ${ }^{23}$ or regulate redox-sensitive proteins and lower BP by acting as an antioxidant. ${ }^{24}$

SOD, an antioxidative enzyme that forms a major cellular defense against superoxide and peroxynitrite formation, has a major role in preventing the pathophysiological effects of superoxide on the vasculature. ${ }^{25}$ Plasma SOD reflects extracellular SOD activity, and reduction of its activity is most likely a consequence of attenuated NO. ${ }^{26}$ This is because extracellular SOD expression is induced by endothelial NO. ${ }^{25}$ Therefore, the favorable impact of black soy peptide supplementation on SOD activity and BP seen in this study could be related to the preservation of $\mathrm{NO}$ bioactivity.

The study of the antioxidative activity of synthetic His-containing peptides derived from proteolytically digested soybean proteins showed that His-containing peptides acted as metal-ion chelators, active-oxygen quenchers and hydroxyl-radical scavengers. Addition of a Leu residue to the $\mathrm{N}$-terminus of a His-His dipeptide enhanced antioxidant activity. ${ }^{27}$ Among multiple biomarkers of oxidative stress, $\mathrm{F}_{2}$-isoprostane levels may be the best biomarker of lipid peroxidation in healthy human subjects. ${ }^{28}$ In the current study, the reduction in plasma MDA and urinary 8-epi- $\mathrm{PGF}_{2 \alpha}$ levels, and the increase in plasma SOD activity, were all significantly enhanced in the $b$ lack soy peptide supplementation group than in the control group. Furthermore, ACE activity was negatively correlated with increased serum total NO and plasma SOD activity. Yang et al. ${ }^{29}$ found lower MDA levels in the hearts and aorta of hypertensive rats treated with soy protein hydrolysate. This indicates that soy protein hydrolysate may improve vascular function not directly by scavenging free radicals but instead by reducing the upstream production of free radicals.

Insulin resistance and the concomitant compensatory hyperinsulinemia may be a major underlying pathogenic mechanism of hypertension. ${ }^{30}$ Noriega-Lopez et al. ${ }^{31}$ demonstrated that soy protein consumption might ameliorate hyperinsulinemia because of unique soy protein amino-acid patterns. Recently, the beneficial effect of black soy peptide supplementation on glucose control was demonstrated in subjects with prediabetes and newly diagnosed type 2 diabetes. $^{2}$ In that study, black soy peptide caused significant decreases in circulating insulin and HOMA-IR indices. Further investigations are required to clarify the effects and mechanisms of black soy peptide consumption on BP related to insulin metabolism and insulin resistance.

Limitations of the current study include the relatively short duration of intervention and the lack of testing for a dose-response relationship between black soy peptide intake and BP changes. Despite these limitations, the present study indicates that black soy peptide supplement reduces SBP compared with a placebo supplement among patients with prehypertension and stage I hypertension. Additionally, black soy peptide supplementation caused improved oxidative stress profiles, including a reduction in plasma MDA and urinary 8 -epi-PGF $\mathrm{PG}_{2 \alpha}$ and an increase in plasma SOD activity. Black soy peptides that we used in the present study had no side effects on the participants. Further studies are still required to clarify the mechanisms of how black soy peptide affects BP. The results of those studies may be used to guide dietary management to prevent and treat hypertension.

\section{CONFLICT OF INTEREST}

The authors declare no conflict of interest.

\section{ACKNOWLEDGEMENTS}

This work was supported by the National Research Foundation of Korea (NRF) funded by the Ministry of Science, ICT \& Future Planning (20062005306, 2010-0015017, and 2012M3A9C4048762).

1 Shin ZI, Yu R, Park SA, Chung DK, Ahn CW, Nam HS, Kim KS, Lee HJ. His-His-Leu, an angiotensin I converting enzyme inhibitory peptide derived from Korean soybean paste, exerts antihypertensive activity in vivo. J Agric Food Chem 2001; 49: 3004-3009.

2 Kwak JH, Lee JH, Ahn CW, Park SH, Shim ST, Song YD, Han EN, Lee KH, Chae JS. Black soy peptide supplementation improves glucose control in subjects with prediabetes and newly diagnosed type 2 diabetes mellitus. J Med Food 2010; 13 . 1307-1312.

3 Jang EH, Ko JH, Ahn CW, Lee HH, Shin JK, Chang SJ, Park CS, Kang JH. In vivo and in vitro application of black soybean peptides in the amelioration of endoplasmic reticulum stress and improvement of insulin resistance. Life Sci 2010; 86: 267-274.

4 Jang EH, Moon JS, Ko JH, Ahn CW, Lee HH, Shin JK, Park CS, Kang JH. Novel black soy peptides with antiobesity effects: activation of leptin-like signaling and AMPactivated protein kinase. Int J Obes (Lond) 2008; 32: 1161-1170.

5 Rho SJ, Park SJ, Ahn CW, Shin JK, Lee HG. Dietetic and hypocholesterolaemic action of black soy peptide in dietary obese rats. J Sci Food Agric 2007; 87: 908-913.

6 Guevara-Cruz M, Tovar AR, Aguilar-Salinas CA, Medina-Vera I, Gil-Zenteno L, Hernández-Viveros I, López-Romero $P$, Ordaz-Nava G, Canizales-Quinteros S, Guillen Pineda LE, Torres N. A dietary pattern including nopal, chia seed, soy protein, and oat reduces serum triglycerides and glucose intolerance in patients with metabolic syndrome. J Nutr 2012; 142: 64-69.

7 Allen N, Berry JD, Ning H, Van Horn L, Dyer A, Lloyd-Jones DM. Impact of blood pressure and blood pressure change during middle age on the remaining lifetime risk for cardiovascular disease: the cardiovascular lifetime risk pooling project. Circulation 2012; 125: 37-44

8 Nakahara T, Sugimoto K, Sano A, Yamaguchi H, Katayama H, Uchida R. Antihypertensive mechanism of a peptide-enriched soy sauce-like seasoning: the active constituents and its suppressive effect on renin-angiotensin-aldosterone system. J Food Sci 2011; 76: H201-H206.

9 van Vark LC, Bertrand M, Akkerhuis KM, Brugts JJ, Fox K, Mourad JJ, Boersma E. Angiotensin-converting enzyme inhibitors reduce mortality in hypertension: a metaanalysis of randomized clinical trials of renin-angiotensin-aldosterone system inhibitors involving 158998 patients. Eur Heart J 2012; 33: 2088-2097.

10 Shin ZI, Ahn CW, Nam HS, Lee HJ, Lee HJ, Moon TH. Fractionation of angiotensin converting enzyme inhibitory peptide from soybean paste. Korean J Food Sci Technol 1995; 27: 230-234.

11 Kwak JH, Ahn CW, Park SH, Jung SU, Min BJ, Kim OY, Lee JH. Weight reduction effects of a black soy peptide supplement in overweight and obese subjects: double blind, randomized, controlled study. Food Funct 2012. 3: 1019-1024.

12 Kim JY, Gum SN, Paik JK, Lim HH, Kim KC, Ogasawara K, Inoue K, Park S, Jang Y, Lee JH. Effects of nattokinase on blood pressure: a randomized, controlled trial. Hypertens Res 2008; 31: 1583-1588.

13 Shim JS, Oh KW, Suh I, Kim MY, Shon CY, Lee EJ, Nam CM. A study on validity of a 299 semiquantitative food frequency questionnaire of Korean adults. Korean J Community Nutr 2002; 7: 484-494.

14 Christian JL, Greger JH. Nutrition for Living. Benjamin/Cummings, Redwood city, CA, USA, 1994, pp. 111

15 The American Dietetic Association. Handbook of Clinical Dietetics 2nd edn. Yale University Press, New Haven, CT, USA, 1992, pp. 5-39.

16 Whelton PK, He J, Appel LJ, Cutler JA, Havas S, Kotchen TA, Roccella EJ, Stout R, Vallbona C, Winston MC, Karimbakas J, National High Blood Pressure Education Program Coordinating Committee. Primary prevention of hypertension: clinical and public health advisory from The National High Blood Pressure Education Program. JAMA 2002; 288: 1882-1888.

17 He J, Wofford MR, Reynolds K, Chen J, Chen CS, Myers L, Minor DL, Elmer PJ, Jones DW, Whelton PK. Effect of dietary protein supplementation on blood pressure: a randomized, controlled trial. Circulation 2011; 124: 589-595.

18 Yang HY, Chen JR, Chang LS. Effects of soy protein hydrolysate on blood pressure and angiotensin-converting enzyme activity in rats with chronic renal failure. Hypertens Res 2008; 31: 957-963.

19 Cooke JP. Therapeutic interventions in endothelial dysfunction: endothelium as a target organ. Clin Cardiol 1997; 20: 45-51.

20 Mann GE, Rowlands DJ, Li FY, de Winter P, Siow RC. Activation of endothelial nitric oxide synthase by dietary isoflavones: role of NO in Nrf2-mediated antioxidant gene expression. Cardiovasc Res 2007; 75: 261-274. 
21 Jochberger S, Dünser MW. Arginine vasopressin as a rescue vasopressor to treat epidural anaesthesia-induced arterial hypotension. Best Pract Res Clin Anaesthesiol 2008; 22: 383-391.

22 Ozturk El, Uma S. Effects of atorvastatin and L-arginine treatments on electrical field stimulation-mediated relaxations in pulmonary arterial rings of monocrotaline-induced pulmonary hypertensive rats. J Cardiovasc Pharmacol 2010; 56: 498-505.

23 Gouvea SA, Bissoli NS, Moysés MR, Cicilini MA, Pires JG, Abreu GR. Activity of angiotensin-converting enzyme after treatment with $\mathrm{L}$-arginine in renovascular hypertension. Clin Exp Hypertens 2004; 26: 569-579.

24 Abdel Baky NA, Zaidi ZF, Fatani AJ, Sayed-Ahmed MM, Yaqub H. Nitric oxide pros and cons: the role of L-arginine, a nitric oxide precursor, and idebenone, a coenzyme- $Q$ analogue in ameliorating cerebral hypoxia in rat. Brain Res Bull 2010; 83: 49-56.

25 Byun JS, Han YS, Lee SS. The effects of yellow soybean, black soybean, and sword bean on lipid levels and oxidative stress in ovariectomized rats. Int J Vitam Nutr Res 2010; 80: 97-106.

26 Vera R, Sánchez M, Galisteo M, Villar IC, Jimenez R, Zarzuelo A, Pérez-Vizcaíno F, Duarte J. Chronic administration of genistein improves endothelial dysfunction in spontaneously hypertensive rats: involvement of eNOS, caveolin and calmodulin expression and NADPH oxidase activity. Clin Sci (Lond) 2007; 112: 183-191.

27 Kitts DD, Weiler K. Bioactive proteins and peptides from food sources. Applications of bioprocesses used in isolation and recovery. Curr Pharm Des 2003; 9: 1309-1323.

28 Tacconelli S, Capone ML, Patrignani P. Measurement of 8-iso-prostaglandin F2alpha in biological fluids as a measure of lipid peroxidation. Methods Mol Biol 2010; 644: 165-178.

29 Yang HY, Yang SC, Chen ST, Chen JR. Soy protein hydrolysate ameliorates cardiovas cular remodeling in rats with L-NAME-induced hypertension. J Nutr Biochem 2008 19: 833-839.

30 Ferrannini E, Buzzigoli G, Bonadonna R, Giorico MA, Oleggini M, Graziadei L, Pedrinelli R, Brandi L, Bevilacqua S. Insulin resistance in essential hypertension. N Engl J Med 1987; 317: 350-357.

31 Noriega-López L, Tovar AR, Gonzalez-Granillo M, Hernández-Pando R, Escalante B, Santillán-Doherty P, Torres N. Pancreatic insulin secretion in rats fed a soy protein high fat diet depends on the interaction between the amino acid pattern and isoflavones. J Biol Chem 2007; 282: 20657-20666.

Supplementary Information accompanies the paper on Hypertension Research website (http://www.nature.com/hr) 